\title{
MODERNIDAD POLÍTICA Y DESILUSIÓN: FREUD Y LA GUERRA
}

\author{
JOSÉ FERNÁNDEZ VEGA
}

CONICET

UNIVERSIDAD DE BUENOS AIRES

Le dije a Wittgenstein que uno de mis conocidos estaba trabajando en una tesis sobre la causa por la que había fracasado la Liga de las Naciones.

"Wittgenstein: iDígale que primero averigüe por qué los lobos devoran a los corderos!"1

Existen dos escritos de Sigmund Freud que abordan directamente el problema de la guerra (además de otros pasajes a lo largo de su obra en los que el fundador del psicoanálisis se refiere de manera circunstancial a ese fenómeno). ${ }^{2}$ Un primer trabajo sobre el tema (formado en verdad por dos textos y una carta) se remonta al año 1915, esto es, poco después del estallido de la Primera Guerra Mundial. ${ }^{3}$ Ante ella como tantos otros intelectuales en toda Europa y particularmente en el área lingüística alemana, Freud comenzó sintiendo un gran entusiasmo que muy pronto trocó por una actitud fuertemente crítica respecto de la guerra en general, según refiere uno de sus biógrafos. ${ }^{4}$ La visión de Freud sobre el conflicto cambió en forma radical

1 M. O'Drury, "Conversaciones con Wittgenstein" (1930?) [sic], en Rush Rhees, Recuerdos de Wittgenstein, Fondo de Cultura Económica, México, 1989, p. 196.

${ }^{2}$ Cfr. por ejemplo, la segunda sección de Totem und tabu [Tótem y tabú] (1915), en S. Freud, Gesammelte Werke, von A. Freud, E. Bibring, W. Hoffer, E. Kris. O. Isakower (eds.), Fischer Verlag, Francfort del Meno, 1961, t. 9 (trabajo de los años 1932-1939) [en adelante citada como GW)]; ed. cast.: S. Freud, Obras completas, trad. J.L. Etcheverry, Amorrortu, Buenos Aires, 1979 , t. 14 [en adelante $O C$ ].

3 "Zeitgemässes über Tod und Krieg" [De guerra y muerte. Temas de actualidad]. GW, t. $10 ; O C$, t. 14.

4 Un análisis clásico de la actitud de generalizado entusiasmo de los académicos alemanes frente a la guerra y hacia las llamadas "ideas de 1914", puede verse en K. Fritz Ringer, $\mathrm{El}$ ocaso de los mandarines alemanes. La comunidad académica alemana 1890-1933, trad. J.M., 
precisamente hacia 1915 cuando fue evidente que la victoria no estaba asegurada por el bando de su país y se difundía una creciente información acerca de las miserias de la vida en el frente. Peter Gay calificó el escrito de Freud sobre el tema de 1915, como un "ensayo de consolación". Con todo, según explica este biógrafo, el fin de las hostilidades trajo novedades positivas para la disciplina que Freud intentaba consolidar, pues la búsqueda de un tratamiento adecuado para los numerosos casos de "neurosis de guerra" declarados despertó, por primera vez, el interés oficial por el psicoanálisis. ${ }^{5}$

El segundo texto freudiano sobre la guerra fue producido en un contexto internacional bien distinto - Adolf Hitler estaba todavía en las vísperas de su acceso al poder- y constituye una carta de respuesta a Albert Einstein quien había elegido dirigirse a Freud en el marco de un intercambio auspiciado por la Liga de las Naciones. ${ }^{6}$ La iniciativa de la Liga de las Naciones estaba orientada a poner en contacto distintas personalidades de la cultura para que dieran su opinión sobre un tema. Einstein escogió el de la guerra y envió a Freud una carta fechada el 30 de julio de 1932 en la que lo invitó a pronunciarse, en tanto psicólogo, sobre el fenómeno bélico y sobre sus posibles vías de solución. En su escrito, Einstein había advertido ya que la mera existencia de un tribunal internacional sin fuerza coercitiva propia para hacer cumplir sus veredictos no lograría acabar con las disputas violentas entre los distintos países; sería preciso que éstos —agregó- renunciasen a

Pomares, Pomares-Corredor, Barcelona, 1995 pp. 175 ss., incluyendo algunas referencias a las posiciones de Freud. Respecto de ellas, cabe señalar que Freud se habría dejado inflamar por el compacto triunfalismo vigente en toda el área cultural alemana al comienzo de la guerra y, típicamente, decayó en su apoyo a medida que el conflicto se evidenciaba una carnicería y los aliados ganaban posicioncs. Uno de sus biógrafos refiere que, acerca de la guerra "Like his followers, Freud too for a time indulged himself in partisan credulity, as cheerful, even tiumphant bulletins kept pouring in from the Front. But he never quite yielded to the irrational, quasi-religious exaltation of a Rilke or a Mann [. . . ] Besides, his lifelong attachment to England got in the way of full-throated chauvinism. He would [...] support the war 'with all my heart, if I did not know that England is on the wrong side'". Peter Gay, Freud. A Life for Our Time, Londres-Melbourne, J.M. Dent \& Sons, 1988, pp. 349-350. La conflagración le causó a Freud numerosos perjuicios profesionales y sumió en la parálisis el desarrollo, todavía incipiente, del movimiento psicoanalítico y de su influencia.

5 P. Gay, op. cit., pp. 375-376. Poco después del final de la guerra (1920) Freud fue convocado por el Ministerio de Guerra austriaco como experto. Un crítico informe suyo sobre el tratamiento que recibían en la medicina oficial las neurosis de guerra (pues los pacientes, al no presentar trastornos físicos, eran considerados simuladores y sometidos a electroterapia) (puede verse en: $O C$, t. 17, pp. 201 y ss). Freud aprovecha también para subrayar el acercamiento de los médicos al psicoanálisis en busca de abordajes para el tratamiento de las neurosis de guerra, en cuyo diagnóstico ve una confirmación al menos parcial de su teoría.

6 "Warum Krieg?" [¿Por qué la guerra?], GW, t. 16; OC, t. 22. El texto fue publicado en 1933. 
parte de su soberanía para que la paz fuera posible. La respuesta de Freud a estas consideraciones está fechada en septiembre de $1932 .{ }^{7}$

Este célebre intercambio epistolar, tanto como el texto freudiano de 1915, pueden interpretarse como documentos tardíos de la historia de las ideas modernas y, más particularmente, Iluministas sobre la guerra. En las líneas que siguen se intentará fundamentar esta visión con base en dos justificaciones: la primera sostiene que en esos textos freudianos vuelven a reflejarse algunos de los asuntos tratados por los modernos al considerar el tema de la guerra, los cuales son explícitamente recuperados por Freud en varias ocasiones (por ejemplo, cuando argumenta sobre el aspecto barbárico-natural de la condición humana). La segunda razón es que dichos asuntos son objeto de una actualización transformadora que intenta rescatarlos como instrumentos de análisis protegiéndolos del anacronismo a los que los expondría su confrontación con una crisis histórica inédita. A partir de la catástrofe que significó la Gran Guerra en la conciencia europea, cuyos efectos se dejaron sentir en cualquier aspecto, el conjunto de valores y de ideas heredados de la cultura Iluminista sufrió una conmoción que en algunos casos condujo a desecharlos por completo y, en otros, a someterlos a algún tipo de reformulación. El pacifismo puede proporcionar un ejemplo adecuado en este sentido. Como conjunto articulado de postulados con aspiraciones prácticas, y no como mero desideratum, el pacifismo es ciertamente una herencia ético-jurídica de la ilustración y de sus precursores inmediatos; pero la encarnación de dicha herencia en un reclamo social generalizado fue una consecuencia de la impresión causada por la hecatombe de 19141918. Como indica Michael Howard, fue sólo a partir de esa experiencia límite que la guerra perdió la aceptación como política normal del estado y la legitimidad de la que hasta entonces se encontraba indiscutiblemente revestida. Aquella crisis europea señaló el origen contemporáneo de las preocupaciones pacifistas como signo ético corriente - no en tanto simple preocupación jurídica- de nuestra cultura. El impacto de la inusitada violencia y destrucción de la Gran Guerra en la conciencia civil tuvo, por tanto, un efecto decisivo. Los- textos de Freud, como se sostendrá aquí, ponen en

7 Cfr. la ácida crítica a esta carta de Einstein que contemporáneamente hizo Bertold Brecht en sus Werke, Francfort del Meno, Suhrkamp, 1992, t. 21; Schriften I (1914-1933), pp. 588-589. Brecht no sólo reprochó a ese texto ignorar las causas sociales de la guerra (concentradas, según él, en el carácter clasista de la sociedad), sino que se manifestó indignado por lo que estimó como su vidente ingenuidad. Para Brecht, este defecto volvía todo el planteo completamente infructífero y, finalmente, nihilista. La crítica, sin embargo, evita una referencia explícita a Freud (fuera del título del pasaje: "Einstein-Freud"), pero se distancia de la interpretación en la que el "Mordlust" [placer de muerte], como escribe Brecht, desempeña un papel fundamental, por encima de los intereses materiales en juego en un conflicto entre estados capitalistas. 
evidencia este hecho. Más específicamente, marcan también una trágica desilusión en la esperanza, firme entre los modernos y todavía activa en las vísperas de la movilización general de 1914, de que el progreso histórico iba a desterrar algún día el conflicto armado internacional. En lugar de encaminar a la civilización hacia una paz perpetua cada vez más cercana, o al menos hacia formas de combate más humanas o menos "irracionales", la evolución civilizatoria había desembocado en la conflagración más sanguinaria de que hubiera memoria. ${ }^{8}$

\section{Guerra y muerte}

En la primera parte de su escrito de 1915, titulada "La desilusión provocada por la guerra", 9 Freud se refiere al decepcionante sentimiento que suscita en el hombre de cultura la comprobación de que la civilización a la que pertenece no puede prescindir de la violencia política. En efecto, la cultura blanca y europea, esto es, la cultura que se concibe a sí misma como mundialmente dominante y se tiene por la más sofisticada de la historia, no suprime el recurso a la violencia bélica y ni siquiera logra hacer menos crueles las formas que ésta adquiere. Como aclara luego Freud, esta "desilusión" significa, en realidad, la destrucción de una falsa ilusión basada en una confianza desmesurada en las potencialidades de la cultura. Tal ilusión tenía finalmente un efecto auto-consolador pues, aunque para la razón política "realista" fuese injustificada, evitaba el displacer en la proyección de una autoimagen humana. Con estas reflexiones Freud parece prolongar los comentarios de Carl von Clausewitz, el autor clásico de la estrategia moderna, acerca de lo que denominaba el filantropismo y las "ideas erróneas" surgidas de la buena voluntad y del sentimentalismo (consideraciones que, más tarde, Friedrich Nietzsche citó con aprobación en sus apuntes). ${ }^{10}$ Para Clausewitz, el humanitarismo en la consideración de temas militares representa un punto de vista ideológico que no contribuye ni al éxito político ni a la adecuada intelección de la situación.

Avanzando todavía en su razonamiento, Freud explica que el estallido de la guerra hace patente al hombre de cultura que el estado mata, y monopo-

8 Michael Howard, The Causes of War, Temple Smith, Londres, 1983, pp. 8-9.

$9 \mathrm{GW}, \mathrm{t} .10 ; O C$, t. 14, pp. 274 y ss. En el mismo tomo de las respectivas ediciones, véase también: "Vergänglichkeit" ["La transitoriedad"] (1915).

10 De la crítica clausewitziana al "filantropismo" en temas militares, cfr. Vom Kriege, Bonn, Dümmlers, 1991, I, 1, 3, pp. 192-194 [trad.: De la guerra, trad. R.W. de Setaro, Solar, Buenos Aires, 1983, pp. 10 ss., en adelante citadas como $V K$ y $D G$, respectivamente]. En cuanto a Nietzsche, cfr. Friedrich Nietzsche, Nachgelassene Fragmente, en Colli y Montinari (eds.), Friedrich/Nietzsche Sämtliche Werke. Kritische Studien Ausgabe in 15 Bänden, Wide Gruyter, Berlín, 1980, verano-otoño, 1883, 10, t. 15 [35], pp. 488-489 (aún inéditos en español). 
liza la muerte social, en abierto contraste con la idea moderno-Ilustrada que caracteriza al estado como instancia de pacificación interior e institución depositaria de valores éticos fundantes de la vida humana en común. En un famoso pasaje, Freud expresa con toda claridad la necesaria estupefacción que asaita a la concepción "tardo-iluminista" (por llamarla así) cuando se confronta con la experiencia de la Primera Guerra Mundial: "El ciudadano particular puede comprobar con horror en esta guerra algo que en ocasiones ya había creído entrever en las épocas de paz: que el Estado prohíbe al individuo recurrir a la injusticia, no porque quiera eliminarla, sino porque pretende monopolizarla como a la sal y al tabaco." ${ }^{11}$ Esta reflexión, que señala una crisis de confianza histórica en el aparato estatal, estaría llamada a tener lo que quizá podría definirse como una descendencia secreta. En el año siguiente al último de la guerra, y durante los acontecimientos revolucionarios que conmocionaron a Alemania, Max Weber pronunció su célebre conferencia titulada "La política como vocación" en la que se manifiesta una convicción similar. Tras citar aprobativamente a León Trotsky, Weber afirma que:

Si solamente existieran configuraciones sociales que ignorasen el medio de la violencia [Gewaltsamkeit] habría desaparecido el concepto de "Estado" y se habría instaurado lo que, en este sentido específico, llamaríamos "anarquía". La violencia no es, naturalmente, ni el medio normal ni el único medio de que el Estado se vale, pero sí es su medio específico. Hoy, precisamente, es especialmente íntima la relación del Estado con la violencia. En el pasado las más diversas asociaciones, comenzando por la asociación familiar (Sippe), han utilizado la violencia como un medio enteramente normal. ${ }^{12}$

Pareciera que la "desilusión" del hombre "culto" referida por Freud, se transformó, inmediatamente después de la guerra, en ácida constatación teórica general: el estado monopoliza la violencia, la centraliza y prohíbe su uso no fiscalizado. ${ }^{13}$ Para Freud, el estado sufre además un proceso de

11 "La desilusión causada por la guerra", en $O C$, t. 14, p. 281.

12 Max Weber, "La política como vocación", en El político y el científico, trad. F. Rubio Llorente, Alianza, Madrid, 1996, p. 83 [orig. "Politik als Beruf", en Gesammelte Politische Schriften, von J. Winckelmann (ed.), J.C.B. Mohr, Tubinga, 1958, p. 494]. (Los paréntesis del texto son del traductor, los corchetes, como en todos los casos que aparezcan en lo sucesivo, son míos.)

13 Es curioso que Weber utilice en esta conferencia la expresion "monopolio", usada por Freud unos años antes, al referirse a la aspiración del estado por controlar de manera exclusiva la violencia política. ¿Implica ello que conociera el texto de Freud? Es imposible ser tan preciso, pero según la biografía que le consagró su esposa (Marianne Weber, Max Deber. Ein Lebensbild, Pieper, Munich, 1989, p. 378) Weber habría valorado las teorías de Freud y en un referato firmado en 1907, declaró conocerlas. Weber consideraba al psicoanálisis como una teoría 
desmoralización al estallar la guerra, un proceso que alcanza por supuesto también al individuo. Se suprime con dicho proceso la "angustia social" o neurosis, necesaria según el psicoanálisis para mantener unida y ordenada la sociedad. La esencia antropológica se muestra entonces al desnudo y las pulsiones agresivas, ya no refrenadas por la ética cultural sino estimuladas por las necesidades bélicas de la política, generan una regresión al primitivismo subjetivo. En el vocabulario de la modernidad podría describirse este proceso como una recaída en el estado de naturaleza por parte de los individuos, los cuales, sin embargo, no abandonan por este acto la sociedad, sino que es el estado mismo quien se los impone como servicio a su defensa. La guerra produce un certero daño en aquello que Freud denomina "aptitud para la cultura", en referencia a esa capacidad social de traducir el egoísmo primitivo del individuo en altruismo e impulso moral (aunque deba por ello pagar el precio de la neurosis). "Dos cosas en esta guerra - escribe Freudhan provocado nuestra desilusión: la ínfima eticidad demostrada hacia el exterior por los Estados, que hacia el interior se habían presentado como los guardianes de las normas éticas, y la brutalidad en la conducta de individuos a quienes, por su condición de partícipes de la más elevada cultura humana [i.e., la occidental], no se los había creído capaces de algo semejante." ${ }^{14}$ En estas palabras se trasluce una amarga comprobación: la del fracaso último del programa Iluminista que había llegado a convertirse en sentido común establecido del hombre civilizado. Dicho programa, si bien intentó dar un fundamento moral al estado y a la política, se mostró impotente para dar una respuesta eficaz al problema de la guerra. Y esta incapacidad implicó su derrumbe como alternativa creíble para el ordenamiento de la sociedad, pues según Freud, entre otros efectos perversos, la guerra provoca una regresión social incontenible que destruye cualquier vínculo y toda barrera ética o jurídica.

Por otra parte una conflagración militar ocasionaría una excitación generalizada cuya inmediata consecuencia es la ceguera intelectual de los individuos. Aunque para Freud éste último es sin duda un fenómeno secundario respecto del derrumbe de las esperanzas Iluministas en la civilización (que cualquier observador honesto podía, según él, constatar en la trágica

científica aún inmadura y en etapa formativa. Criticaba de ella sus implicaciones morales y sus presupuestos valorativos. Sobre las relaciones de Weber con Otto Gross, un díscolo discípulo de Freud, puede verse Martin Green, The von Richthofen Sisters, Basic Books, Nueva York, 1974. Una comparación general entre los dos autores, que resalta el común pesimismo de sus análisis sociales es la de Tracy B. Strong, "Weber and Freud: Vocation and Self-acknowledgment", en W.J. Mommsen y J. Osterhammel (eds.), Max Weber and His Contemporaries, Allen and Unwin, Londres, 1987. (Agradezco al doctor Michael Steinberg de Chicago sus valiosas indicaciones sobre Weber y Freud.)

14 "La desilusión...", OC, t. 14, p. 282. 
realidad europea del momento), lo consideraba, de todos modos, muy pernicioso porque adulteraba la capacidad de mantener una actitud intelectual crítica e independiente. El conflicto bélico pondría las pasiones por encima del reconocimiento de la verdad objetiva, y no sólo de ella sino también de los propios intereses materiales de una sociedad. Freud advierte que ni siquiera el desarrollo del comercio fue suficiente para poner un freno a la guerra. En esta observación pone de manifiesto la magnitud de la herencia ilustrada recibida, bien que nunca explícitamente tratada por Freud. La idea de que la expansión de la actividad comercial llevaría a poner fin a las guerras surgió en el siglo xviI entre los enciclopedistas y se manifestó con especial énfasis en Benjamín Constant y otros pensadores, dominados todos por la confianza, que se revelaría de largo aliento histórico, en una pax mercatorum. Dicho sea de paso, esta noción se encuentra aún muy presente en nuestros días cuando, por ejemplo, entre los beneficios de creación de bloques comerciales, uniones aduaneras y económicas se enumera en lugar destacado la ganancia en términos de seguridad para las regiones donde se producen.

Freud concluye su reflexión ampliando el alcance de las conclusiones a las que arribó en el análisis de la guerra considerándolas válidas para describir rasgos antropológicos permanentes. La imagen final que se desprende de esta operación es una visión política desencantada. En su opinión, ni los estados ni los individuos sienten compulsión exterior alguna hacia la adecuación de sus conductas agresivas instintuales a una regla moral o al cálculo del benéfico de su propio interés material. Los estados támpoco sufren coacción ya que no existe un poder jurídico internacional como cuerpo monopolizador de la violencia física que los obligue a cumplir con el derecho de gentes. ${ }^{15}$ En esta concepción, el Estado queda configurado como una institución amoral, sin restricciones legales externas. Esta imagen implica ciertamente un escándalo cultural para la tradición occidental y para las aspiraciones ético-jurídicas que los autores Ilustrados dejaron como herencia política. La hecatombe bélica lleva a Freud a tomar distancia de los ideales optimistas y revolucionarios del siglo xviI, acercándolo a una visión realista, típica de momentos de desaliento histórico.

Fue en uno de esos momentos, la época de la Restauración que siguió a la derrota de Napoleón, que Clausewitz forjó su teoría de la guerra que la crítica coincide en calificar como realista. En Vom Kriege, su famoso tratado publicado póstumo a partir de 1832, elaboró la diferencia entre las

15 "La desilusión...", op. cit, p. 289: "Habíamos esperado, es cierto, que la grandiosa comunidad de intereses establecida por el comercio y la producción constituiría el comienzo de una compulsión así [i.e., a la eticidad y a la paz] no obstante, parece que en esta época los pueblos obedecen más a sus pasiones que a sus intereses." 
pasiones hostiles populares que se manifiestan en los conflictos militares diferenciándolas de las actitudes hostiles de la institución estatal sometida a la inteligencia estratégica de la política. Para Clausewitz las pasiones populares constituían un ciego impulso natural (blinder Naturtrieb; en traducción "psicoanalítica", una ciega pulsión). ${ }^{16}$.En esta distinción se advierte todavía un motivo Ilustrado que presenta, de manera típica, al pueblo como un cuerpo esencialmente incontinente, aunque subordinado a una instancia política gubernamental "inteligente" que lo dirige (y a fin de cuentas también lo regula y lo modera), orientándolo de manera racional al logro de unos fines instrumentales establecidos por las necesidades estatales. ${ }^{17}$ Para Freud, como se vio, no se puede contar con los individuos (pues se muestran incapaces de identificar sus intereses), pero tampoco con el estado, pues éste se muestra tan inclinado a abandonarse a las propias pulsiones como sus gobernados. Además, como ya se aclaró, el estado no reconoce fuera de él ninguna instancia moral ni ley a la que deba sujetarse. Clausewitz inició su trabajo teórico después del hundimiento definitivo en Waterloo de las promesas revolucionarias que aún quedaban en pie; Freud escribió en el momento en que una guerra que todos presumían de rápido desenlace había entrado en una impasse política y militar, generando un infierno de batallas de material entre posiciones militares estancadas. El siglo que media entre una coyuntura histórica y la otra no sólo señaló un cambio tecnológico, sino una política de la mayor importancia: la crisis de legitimidad del estado. Si para el general prusiano Clausewitz el cuestionamiento del estado como tal es todavía un tema ajeno a su horizonte de reflexión, cien años más tarde el doctor Freud, patriota y entusiasta en 1914, identifica ya en 1915 que el tema se halla en el centro de la crisis a él contemporánea. Poco después sería Max Weber quien retomaría el problema, haciendo con su tratamiento un aporte sustantivo a la reflexión política de nuestro siglo, la cual, desde entonces, no dejó de ocuparse de la legitimidad. ${ }^{18}$

$16 V K$, I, I, I, 28, pp. 212-213; DG, pp. 25-26.

17 León Rozitchner hizo en Argentina una comparación aguda, y muy original en el contexto de la bibliografía internacional, entre el análisis clausewitziano de los sujetos sociales intervinientes en la guerra y sus roles con la estructura del aparato psíquico según Freud. Cfr., L. Rozitchner, "De la política a la guerra: Clausewitz", cap. II de Perón entre la sangre y el tiempos, CEAL, Buenos Aires, 1985 y "Clausewitz y Freud: La guerra y el poder. El duelo como esencia de todo conflicto", en Freud y el problema del poder, Plaza y Valdés-Folios, México, 1987.

${ }^{18}$ Cfr. "Estado y poder en Max Weber", en Norberto Bobbio, Estudios de historia de la filosofía. De Hobbes a Gramsci, trad. y comp. A. Ruiz Miguel, Debate, Madrid, 1985 pp. 257 ss. Para Bobbio el tema de la legitimidad es el mayor aporte de Weber al pensamiento político contemporáneo. 


\section{No mataréis}

Una segunda parte del texto freudiano de 1915, titulada "Nuestra actitud hacia la muerte", intenta profundizar un aspecto de las consecuencias de la guerra en el nivel subjetivo. La función de la sociedad humana, parece decir Freud, consiste básicamente en "Eliminar la muerte de la vida". ${ }^{19}$ Esta idea se asimila (pero también radicaliza en sus conclusiones) a lo que los modernos entendieron como esencia'de la política. En efecto, para ellos el fin último de la reunión de los hombres en sociedad es el de erradicar la muerte violenta de la vida en común en el marco del estado. Éste debe controlar la violencia privada, reduciéndola al silencio o canalizándola y confinándola, bajo la forma de violencia militar, a los límites de la ciudad en sus conflictos con el extranjero, según el modelo de la polis clásica. Freud extrema las implicaciones de esta noción moderna concluyendo que la política, al pretender configurar un espacio abierto y pacífico garantizado por el poder del estado, se convierte asimismo en una ilusoria negación de la finitud individual pues intenta también suprimir la idea misma de la muerte. Ello incluye, por supuesto, tanto la representación de la muerte propia como la inclinación a dar muerte a otros. El primer mandamiento, "no matarás", es, para Freud, proporcionalmente contrario al primer impulso humano hacia el asesinato. En esta definición freudiana late también una antropología filosófica de signo típicamente moderno y negativo que, sin esfuerzo, puede compararse a la de Thomas Hobbes, por ejemplo.

La ilusión básica mediante la cual, según Freud, la teoría política moderna se concebía a sí misma -es decir, como si fuera la superación civilizatoria de la barbarie primitiva- había sido puesta en crisis con el estallido del conflicto bélico. La guerra restituía al hombre político su finitud y a la sociedad su brutalidad. Freud apunta que sólo en las ficciones se sabe morir, y que la muerte en la guerra (es decir, en la política) "ya no se deja desmentir". ${ }^{20}$ En su opinión, ello representaría la contracara de lo que sucede con el tema de la muerte del ser amado, frente a la cual le es socialmente permitida al individuo una negación que dura lo que el trabajo de duelo mediante el cual se inicia el proceso de aceptación subjetiva de ese hecho doloroso. Pero el inconsciente, explica Freud, no cree en la propia muerte y parece afirmar ante ella: "Eso nunca puede sucederte a ti." Esta actitud contribuye también a explicar el arrojo heroico. Desoyendo el razonable consejo de Séneca, que Freud evoca, el héroe no cree que lo que a algún hombre pueda sucederle, pueda sucederle a cualquiera. "No a mi", dice el audaz antes de lanzarse al riesgo. Es en ese instante cuando la muerte se presenta en toda su irrealidad

19 "La desilusión...", op. cit., p. 290.

20 Ibid., p. 292. 
como negación aniquiladora de la vida, negación que, por cierto, no es privativa del intrépido. Freud termina su escrito con lo que parece un llamado al realismo psicológico: "Recordamos el viejo apotegma 'Si vis pacem, para bellum': Si quieres conservar la paz, ármate para la guerra. Sería tiempo de modificarlo: 'Si vis vitam, para mortem': Si quieres soportar la vida, prepárate para la muerte." 11

De acuerdo con la sintesis que ofrece Franco Fornari, para Freud, "la guerra constriñe a los hombres a desilusionarse del valor de su civilización en cuanto los conduce a descubrir la barbarie que creen haber superado: [Freud] hace notar irónicamente que aun esta impresión nuestra de que la guerra nos hace caer muy bajo, en la barbarie, es a su vez ilusoria, porque en realidad no hemos llegado tan alto como pensamos; en suma, la barbarie siempre ha estado presente en nuestro inconsciente". ${ }^{22}$ La guerra, pues, desnuda la cultura y la pone en contacto con lo que, según el psicoanálisis, son sus raíces barbáricas, reducidas en tiempos de paz a un estado latente. Estos fundamentos culturales negativos no han sido superados - como ilusoriamente (o con mala fe) cree el hombre de cultura imbuido de ideales Iluministas- sino que apenas se encuentran recubiertos por constricciones éticas (que, según el psicoanálisis, orienta el instinto agresivo hacia el interior humano posibilitando la cultura pero generando neurosis) o por el miedo a la sanción o al descrédito sociales. Al vivir respirando una atomósfera de ilusiones, cuyo origen moderno e ilustrado es evidente, la cultura europea, concluye Freud, vive en realidad muy por "encima de sus recursos psicológicos".

Estos términos se reafirman en otro texto de la misma época, una breve carta al médico holandés Van Eeden, fechada en diciembre de 1914, apenas unos meses después del estallido de la Primera Guerra. ${ }^{23}$ Aquí se afirma, pero todavía sin las amargas derivaciones que ello adquiriría luego, que la guerra afecta el orgullo por la cultura y que, según una tesis psicoanalítica fundamental, lo primitivo no es superado por la civilización, como postulaba la idea Iluminista de progreso, sino sólo reprimido y pronto a liberarse.

Un cuarto texto freudiano, titulado "La transitoriedad" y publicado en 1916 en ocasión de un homenaje colectivo a Goethe, retoma el tema de la muerte y el de su admisión subjetiva y cultural, lo que para Freud es sin duda un signo positivo de madurez intelectual y humana. Con un estilo que le ganó la reputación como uno de los mayores prosistas en su lengua,

21 "Vergänglichkeit" ["La transitoriedad"], op. cit., (1916) y "Nuestra actitud hacia la muerte" (segunda parte de "De guerra y muerte. Temas de actualidad", en $O C$, t. 14, p. 301.

22 F. Fornari, Psicoanálisis de la guerra, trad. L. Lara y R.M.A. de Lara, Siglo XXI, México, 1972, p. 109.

23 oc, t. 14, pp. 302-303. 
Freud explica que el carácter efímero de la vida no le resta encanto sino que, por el contrario, refuerza nuestro interés en ella. Lo que está destinado a perecer es por ello más valioso; el límite temporal de la existencia, parece decir Freud, invita a una especial intensidad en la experiencia vital, no a la romántica renuncia anticipada a la tierra. En esta explicación, la consigna freudiana "si quieres soportar la vida, prepárate para la muerte" pierde, al menos en parte, el carácter lóbrego que podría en principio atribuírsele.

\section{La respuesta a Einstein}

Casi dos décadas más tarde, en su carta de 1932 a Albert Einstein, Freud vuelve a manifestar un interés político en el análisis del drama de su tiempo:

Comienza usted -escribe en respuesta a su corresponsal- con el nexo entre derecho y poder [Recht und Machit]. Es ciertamente el punto de partida correcto para nuestra indagación. ¿Estoy autorizado a sustituir la palabra "poder" por violencia ["Gewalt"], más dura y estridente? Derecho y violencia son hoy opuestos para nosotros. Es fácil mostrar que uno se desarrolló desde la otra, y si nos remontamos a los orígenes e investigamos cómo ocurrió eso la primera vez, la solución nos cae sin trabajo en las manos. ${ }^{24}$

Freud subraya aquí una oposición conceptual entre justicia y arbitrariedad, al tiempo que evidencia una aguda percepción de las relaciones entre poder y violencia. ${ }^{25}$ La tensión entre estos últimos términos se volverá a hallar, de manera implícita, en la primera y casi enigmática definición clausewitziana de la guerra como acto de violencia, pero también como acto de poder. "La guerra es, en consecuencia, un acto de fuerza [Akt der Gewalt] para imponer nuestra voluntad al adversario." ${ }^{26}$ La versión castellana vierte la polisémica voz Gewalt como "fuerza"; aunque lo mismo podría traducirse por "poder" o "violencia" (o incluso "derecho", en el sentido de violencia del estado, poder jurídico o incluso poder político).

24 “¿Por qué la guerra?", $O C$, t. 22, pp. 187-188.

25 Sobre la oposición entre justicia y arbitrariedad, cfr. la entrada "justicia" en Höffe Ottfried, Diccionario de ética, trad. J. Vigil, Grijalbo, Barcelona, 1994, p. 295. Freud no profundiza en su texto el vínculo entre poder (o violencia) y derecho, que da por descontado. En la lengua alemana, sin embargo, la relación pervive de manera más patente que en la castellana. Gewalt posee a veces el sentido jurídico de potestas, como cuando se habla de la patria potestad o del poder soberano del estado (Elterngewalt, Staatsgewalt).

26 VK, I, I, 2, pp. 191-192; DG, p. 9. Cfr. también la definición weberiana de poder, en la que $\mathrm{H}$. Arendt encontró un vínculo con la clausewitziana de la guerra: M. Weber, Economía y sociedad, trad. J. Medina Echevarría et al., Fondo de Cultura Económica, Buenos Aires, 1992, 1a. parte, I, 16, p. 43; y H. Arendt, "Sobre la violencia", en Crisis de la república, trad. G. Solana, Taurus, Madrid, 1973, p. 139. 
Pero que para Freud la guerra es en definitiva un acto de poder queda evidenciado en la explicación con la que prosigue su ensayo. En ella sostiene que en la guerra se trata de dominar al enemigo, arriesgando la propia seguridad en aras del interés, en lugar de sucumbir a la tendencia pulsional a matarlo. ${ }^{27}$ Aunque no hay registro de que Freud haya leído a Clausewitz, su comentario guarda una vez más cierta relación con la noción que aparece en Vom Kriege cuando se sostiene que el objetivo de la guerra no es principalmente, como una imagen corriente nos podría llevar a suponer, la destrucción física del oponente, sino más bien el dominio de su voluntad y la rendición de su fuerza moral (i.e., su ánimo para oponer resistencia). Estos objetivos pueden lograrse con una aplicación mayor o menor de violencia y ocasionando un daño variable al adversario, incluyendo por supuesto (en grado creciente) el perjuicio a su fuerza material, a su integridad física personal y atar a su propia vida. ${ }^{28}$ Con esto, Clausewitz - como también Freud - no hace sino continuar la línea de reflexión de Montesquieu y Rousseau, para quienes era claro que el fenómeno bélico no estaba puramente orientado a la aniquilación, sino, ante todo, al dominio político. ${ }^{29}$

La reflexión freudiana, como pudo verse en la cita reproducida más arriba, tampoco parece hacerse muchas ilusiones políticas respecto del derecho, al que define como "poder de la comunidad" llevada a unirse de modo permanente para hacer frente a la violencia superior de un "uno". El derecho continuaría siendo violencia, pero aplicada en nombre de la comunidad. ${ }^{30}$ Se advierte, sin embargo, que en el interior de dicha comunidad se verifican también desigualdades de poder que conducen a la violencia, y esto a pesar del imperio del derecho. Nuevamente este conjunto de ideas se aproximan a las del realismo político de Max Weber (a quien Freud tampoco se refirió jamás explícitamente). ${ }^{31}$

En suma, según Freud, el solo derecho no es suficiente para garantizar la paz. Como los pensadores Iluministas - piénsese en el Kant de Sobre la paz perpetua-, Freud entiende el marco jurídico internacional como condición formal necesaria. Pero, a diferencia de ellos, la considera también políticamente insuficiente, si bien acepta, en coincidencia con Einstein, que una

27 “¿Por qué la guerra?", op. cit., p. 188.

$28 V K, \mathrm{I}, \mathrm{I}, 2$, pp. 225-226; DG, pp. 34-35.

29 Para Montesquieu, cfr. De l'esprit des lois, en Oeuvres complètes, M.A. Masson (ed.), Nagel, París, 1950, t. I, , X, III ss. Para Rousseau: Oeuvres politiques, Jean Roussel (ed.), Garnier, París, 1989 "Fragments sur la guerra", p. 208, donde afirma que la muerte es más bien un medio, no siempre imprescindible, para la victoria militar; se mata para vencer, y no viceversa.

30 "¿Por qué la guerra", op. cit. p. 189.

31 Sobre el realismo de Weber, cfr., entre otros, N. Bobbio, loc. cit. 
"violencia central", en manos de la Liga de las Naciones, y revestida de auténtico poder de ejecución, podría promover la paz. Después de considerar el clásico tema de la conquista militar como origen de la soberanía y de su juridicidad, Freud concluye que: "Se yerra en la cuenta si no se considera que el derecho fue en su origen violencia bruta [robe Gewalt] y todavía no puede prescindir de apoyarse en la violencia." 32

Freud vuelve sobre el problema de la existencia en el sujeto de una pulsión destructiva, de la que ya se había ocupado veinte años antes en su otro escrito sobre la guerra. Esta pulsión, explica, proporciona el placer de agredir y se opone al Eros, término con el que el psicoanálisis designó al principio de la vida. Como ya se anticipó aquí, la denominada conciencia moral es, en su opinión, precisamente el resultado de dirigir "hacia adentro" aquella fuerza agresiva. ${ }^{33} \mathrm{El}$ reconocimiento por parte del psicoanálisis de la violencia y la agresión humanas como situadas en un nivel antropológico profundo, instintual, hace imposible pensar en su erradicación completa de la realidad social. Para Freud la idea de la desaparición de la agresión es o una ilusión bucólica o una utopía "bolchevique". ${ }^{34}$ Con todo, en su opinión, puede aún avanzarse en la prevención de la guerra mediante la contención de los desbordes agresivos y a través del fortalecimiento de lazos emocionales entre los hombres, identificaciones positivas que, como las religiones, promueven el Eros. ${ }^{35}$ En respuesta a los interrogantes de Einstein sobre las posibilidades de la paz, Freud agrega que los propios dirigentes políticos mundiales deberían empezar por someter sus propias pulsiones a "la dictadura de la razón". 36

El escrito freudiano dirigido a Einstein finaliza manifestando su impresión, típica de la época, acerca de los límites que la tecnología bélica pone al despliegue heroico del individuo. Una de las lecciones de las batallas de material entre naciones industrializadas de 1914-1918 fue que la guerra moderna no dejaba mucho espacio al heroísmo, y que más bien anunciaba el mutuo exterminio. En las últimas consideraciones de su carta, Freud vuelve a señalar que el enfrentamiento militar contradice el proceso de la cultura y las "actitudes psíquicas" (interiorización de la inclinación a agredir, etc.) que ese proceso genera. De ello se deriva que el rechazo a la guerra sea

32 “¿Por qué la guerra?”, op. cit., p. 192. Para la relación entre derecho y violencia, puede verse el famoso escrito de Walter Benjamin: "Zur Kritik der Gewalt" ["Para una crítica de la violencia"], en Gesammelte Schriften, Suhrkamp, Francfort del Meno, 1980, II, 1, p. 190, donde se afirma que la violencia (cuyo modelo es siempre la violencia bélica) cumple el papel de creadora de derecho o de conservadora del mismo.

33 "¿Por qué la guerra?", op. cit., p. 194.

34 Ibid., P. 195.

35 Ibid.

36 Ibid., P. 196. 
constitutivo en el hombre de cultura, en cuya figura prototípica se reúnen, según Freud, capacidad intelectual y renuncia pulsional. Todo lo que promueve la cultura, en el sentido amplio que esta noción adquiere para el psicoanálisis, "trabaja también contra la guerra". ${ }^{37}$

\section{Conclusión}

No todas las guerras, en la visión de Freud, pueden valorarse de igual manera. Hay guerras de pillaje y destrucción, que sólo merecen un rechazo terminante, mientras que otras poseen positivos efectos civilizatorios. En esta opinión matizada se refleja también la ambigüedad de la consideración que la modernidad política hizo del conflicto bélico. Si por un lado la guerra fue denunciada como regresión barbárica, indigna de la civilización en progreso; por el otro se admitió que los fines de dicha civilización se veían a veces beneficiados por la conflagración militar entre los hombres. Freud llega incluso a advertir en la guerra un medio para la conquista de la paz perpetua. El comentario no está, en su caso, exento de ironía, y la broma, como se recordará, es similar a una de las pocas que Kant se permite en sus escritos: la paz perpetua, anota al inicio de su texto homónimo, puede ser entendida como aquélla de los cementerios. ${ }^{38}$ Pero incluso Kant, autor del más influyente manifiesto pacifista en una época en que este género proliferó, argumentó con toda seriedad que si bien desde el punto de vista del individuo la guerra siempre representaba una tragedia y una inmoralidad, desde el punto de vista de la especie humana había que reconocer que algunas guerras fueron un motor de progreso. En estos casos, la "naturaleza providencial" se valía del bárbaro medio de la guerra para reunir a los hombres en comunidades estables, lo que significaba un adelanto respecto del puro estado de salvaje aislamiento individual que imaginaba como situación de partida natural del género humano. Así, la guerra y, en general, el conflicto, se convirtió para el más influyente filósofo moderno del siglo xvir y reconocido defensor del carácter ético y jurídico de la paz, en un hilo conductor para interpretar el desarrollo histórico. Según Kant, las consecuencias de la guerra no deben incluirse todas en el saldo negativo de la condición humana. ${ }^{39}$ De modo similar, Freud entiende que la guerra instaura dominios políticos amplios y centralizados, en los que suele imperar la paz, aunque en ellos la estabilidad no está garantizada de una

37 “¿Por qué la guerra?", op. cit., p. 198.

38 Immanuel Kant, Immanuel Kant Werkausgabe in 12 Bänden, von W. Weischedel (ed.), Suhrkamp, Francfort del Meno, 1994, XI, p. 195, BA 3, 4; Sobre la paz perpetua, trad J. Abellán, Tecnos, Madrid, 1991, p. 3.

39 I. Kant, Werkausgabe, op. cit., XI, p. 34, A 385, 386; Filosofía de la historia, trad. E. Ímaz, El Colegio de México, México, 1941, p. 42. 
vez y para siempre. Su afirmación de que la guerra puede traer aparejada una paz duradera si su conducción se unifica en un solo cuerpo político contenía una paradoja "kantiana" de la que fue consciente, a saber, que sólo la guerra (orientada, es verdad, en una cierta dirección) podría acabar con la guerra. ${ }^{40}$

La valoración positiva del conflicto militar desde una perspectiva histórica general realizada por Freud en sus escritos sobre la guerra repite también otro de los temas modernos tratado, como se acaba de ver, por Kant, entre otros pensadores. En la mirada político-histórica de Freud, junto con una formidable originalidad de perspectiva, parece identificarse una constelación problemática cuyas raíces, sin embargo, se reconocen en la tradición política moderna. La consideración del tema de la conquista es otro tema de la discusión sobre la guerra en los siglos xvi y xvil retomado por el fundador del psicoanálisis. ${ }^{41}$ Además, se encuentra en Freud una crítica de los límites del derecho, y el señalamiento - clásico en todo un linaje del pensamiento político- de su origen fundamentalmente violento y no consensuado. Esta consideración, empero, es seguida por una rehabilitación: el derecho es una necesidad social para impedir la mutua destrucción.

La idea freudiana de la sociedad, que se elabora a lo largo de varios años y que, por cierto, influye claramente en su imagen de la guerra, se debate entre dos polos: el representado por la identificación interhumana (y en definitiva por el amor o Eros) y el de la pulsión agresiva (o muerte). La sociedad, concebida como reunión erótica, establece lazos intersubjetivos sobre la base del sentimiento; mientras que la sociedad entendida como tensión se funda en la violencia. Aunque en Freud estas visiones rivales de la sociedad buscan una base biológica (y no deliberada o inconscientemente metafísica como en los autores políticos modernos), dichas nociones no son por cierto nuevas en la historia de las ideas políticas. En la modernidad se hacen ambas presentes en la corriente iusnaturalista que busca terminar con el flagelo de la guerra sobre la base de una asociación duradera, si no fundada en el amor mutuo, al menos sí en alguna forma de reconocimiento recíproco que obligue a deponer las armas y a renunciar a la agresión desnuda, características del estado natural.

En el psicoanálisis, la nota distintiva respecto del venero moderno del que se alimenta, vino dada por el carácter del drama histórico al que su

40 “iPor qué la guerra?”, op. cit., p. 191.

41 De hecho, Montesquieu (cfr. los pasajes a los que remite la nota ut supra) es el único pensador moderno de peso que sostiene la licitud de la Guerra de conquista, argumento que le valdría ácidas críticas por parte de Rousseau y Voltaire (en el artículo "Guerra" de su Dictionaire philosophique), quienes representan la corriente dominante en este tema dentro del pensamiento ilustrado, corriente que encontrará eco en las opiniones de Freud. 
emergencia y desarrollo teóricos como disciplina fueron contemporáneos. En otras palabras, como es notorio la eclosión de la Gran Guerra puso en crisis la idea de progreso heredada del optimismo histórico evolucionista de los siglos anteriores. Como señala Niethammer, la impresión que causó la enorme destrucción de la Primera Guerra Mundial se tradujo, en Freud, en una revalorización teórica del impulso destructivo y en un abandono de la idea de perfectibilidad humana. ${ }^{42}$ Con todo, esta nota pesimista significó una ganancia en términos de profundidad crítica respecto de la vida social, pero el desaliento que trasuntaba derivó en un escepticismo respecto de las posibilidades para la paz desde la óptica del psicoanálisis. El realismo político que imponía la teoría era, de acuerdo con esta perspectiva, resistido por la conciencia moral del individuo; el propio Freud sostenía el pacifismo como una íntima (o mera) convicción ética.

$\mathrm{La}$ ambivalencia freudiana ante el tema de la guerra (que intenciona asimismo el del futuro del hombre según el psicoanálisis) puede sintetizarse en la tensión entre dos convicciones discordantes. Por un lado, su fidelidad básica a la idea Iluminista que postulaba la dictadura de la razón sobre la naturaleza como difícil pero única salida civilizatoria para la especie humana. Tomando distancia de la ingenuidad racionalista de los pensadores de la Ilustración, para Freud fue siempre evidente que ese control "dictatorial" de los impulsos provocaba variadas reacciones negativas en el individuo, la principal de las cuales era la generación de un malestar cultural perenne. Por otra parte, la segunda convicción, discordante con la anterior, se derivaba de un impulso político y teóricamente realista. Dicho impulso llevó a Freud a desilusionarse con las perspectivas de progreso heredadas, las cuales se mostraban frágiles al confrontarse con las atroces dimensiones de la realidad que se ofrecía a sus ojos. Al empeñarse en mostrar la debilidad intrínseca de esas perspectivas para dar cuenta de la vida histórica de su época, Freud hizo vacilar las promesas modernas de una vida humana no dominada por la agresión y la muerte social.

Recibido: 7 de diciembre de 1999

42 Lutz Niethammer, Posthistoire. Ist die Geschichte zu Ende?, Rowohlts, Hamburgo, 1989, pp. 53 ss. 